\title{
BIJDRAGE TOT DE KENNIS VAN DE AVIFAUNA VAN CURAÇAO EN BONAIRE
}

\author{
DOOR \\ G. J. VAN OORDT \\ Zoölogisch Laboratorium der Rijksuniversiteit te Utrecht
}

Hoewel ik in het voorjaar van 1948 slechts korte tijd op Curaçao en Bonaire verbleef, deed ik hier naast waarnemingen, die een bevestiging zijn van die van Rutren (193I), ook een aantal aanvullende observaties. Ik wil deze gaarne publiceren in de feestbundel ter ere van Prof. Dr. J. E. W. Ihle en Prof. Dr. L. F. DE BEAUfort, met wie ik gedurende vele jaren op verschillend gebied zo aangenaam samengewerkt heb.

Over de vogels der Benedenwindse Eilanden is nog slechts weinig geschreven. Eigenlijk bestaat er slechts één goed artikel en wel dat van RuTteN (1931), die hierin niet alleen oude mededelingen van HARTERT en van CORY verwerkte, maar ook tal van nieuwe, eigen waarnemingen, deels van veldornithologische aard, mededeelde. De lijst van DE Jong (1948) is min of meer een uittreksel van die van RUTTEN ${ }^{1}$ ) en bevat slechts enkele eigen aanvullende gegevens.

Ik nam van I8 Febr.-28 Febr. op Curaçao en van 28 Febr.-I Maart I948 op Bonaire waar. Ik maakte hier dus het begin van de voorjaarstrek mede, hetgeen moge blijken uit het vrij talrijk voorkomen van vele in de Arctis broedende Limicolen, van in Noord-Amerika broedende roofvogels zoals Visarenden (Pandion haliaetus carolinensis) en Slechtvalken ( $F a^{\prime} c o$ peregrinus anatum) en van de N.-Amerikaanse Bandijsvogel (Ceryle alcyon).

Bonaire is voor waarnemingen betref fende Limicolen veel beter dan Curaçao, vooral nu de vogels het Schottegat tengevolge van de werkzaamheden der Curaçaose Petroleum Industrie Maatschappij geheel mijden. Slechts de Aalscholvers (Phalacrocorax olivaceus) komen hier nog geregeld nabij het Directiegebouw der C.P.I.M. rusten, zonder zich hier echter te water te begeven! In het onderstaande heb ik mij, wat volgorde en nomenclatuur betreft,

1) Hier en daar zelfs woordelijk dezelfde! 
geheel aangesloten bij Peters' 'Check-list of Birds of the World', vol. I-6 (I93I-I948).

Fregata magnificens L. Op 22 Februari 1948 hield een 20-tal adulte en volwassen, jonge Fregatvogels zich op in de mangroves van het eilandje in de St. Jorisbaai (Curaçao). Duidelijk was te zien, dat enkele vogels naast nesten zaten en daar er verschillende, $0^{7} 0^{\circ}$ met rode keelzak rondvlogen, moet ik wel aannemen, dat de Fregatyogel hier in klein aantal in 1948 gebroed heeft: DE Jong maakt van het voorkomen van de Fregatvogel op dit eilandje eveneens melding, doch heeft er nooit nesten kunnen vinden (1948, p. 3).

Ook op Bonaire zagen we een groot aantal Fregatvogels in de mangroves bij hun nesten zitten en wel in die van de Lagune Lac (29 Febr. I948).

RuTten zegt, dat deze interessante vogels noch op Curaçao noch op Bonaire broeden. Het is jammer, dat wij door gebrek aan een vaartuig geen gelegenheid hadden bovenstaande plaatsen nader te bekijken.

Casmerodius albus egretta (Gmelin). Volgens Rutten niet talrijk op Curaçao. Volgens De Jong op de drie Benedenwindse Eilanden voorkomend. Wij zagen 2 of 3 ex. op 27 Februari aan de baai van St. Kruis (Curaçao).

Hydranassa tricolor. Volgens Peters (Check-list I, p. II3) broedt Hydranassa tricolor ruficollis (Gosse), d.i. de noordelijke subspecies, op Aruba, terwijl dit volgens RutTen en De Jong Hydranassa tricolor tricolor (P. L. S. Müller) zou zijn. Ik kon dit niet nader uitmaken; wij zagen slechts enkele ex. op 21 en 27 Februari, resp. in de St. Martha- en St. Kruis-baai (Curaçao).

Florida coerulea (L.). Van deze soort zagen wij behalve witte ook een vrij groot aantal uitgekleurde, dus blauwe exemplaren aan de St. Martha-baai op 2I Februari en aan de baai van St. Kruis op 27 Februari I948. Witte exx. van deze soort gelijken oppervlakkig gezien veel op Leucophoyx th. thula (Molina). Hun wijze van vissen is echter veel bezadigder dan die van de Kleine Egret, welke hierbij veel door het ondiepe water heen en weer loopt.

Phoenicopterus ruber L. Hoewel Gezaghebber KrUgers ons kon mededelen, dat de Flamingo in 1947 op Bonaire was teruggekeerd - nadat hij er gedurende de oorlog verjaagd was -, hadden wij niet veel geluk met deze soort : op 28 Maart 1948 zag ik 2 exx. in het Pekelmeer en op 29 Maart I3 exx. in Goto. Het is mij nog niet bekend, of de Flamingo in 1948 wederom op Bonaire gebroed heeft.

Buteo albicaudatus colonus Berlepsch. Deze fraaie buizerd komt nog steeds in betrekkelijk groot aantal voor op het $\mathrm{N}$. gedeelte van Curaçao, speciaal bij de St. Christoffel (375 m). Rutten (I93I, p. 125) deelt mede, dat hij hier ook een geheel zwarte buizerd heeft gezien (,grootte en vliegbeeld precies als van den Witstaartbuizerd. Alleen op den staart een aantal leigrijze dwarsstrepen"). Ook wij zagen deze donkere buizerden, die door DE Jong (I948) 
voor Buteo albonotatus worden gehouden. $\mathrm{Nu}$ zijn juv. exemplaren van de Witstaartbuizerd zeer donker (zie o.a. R. T. Peterson, I94I, p. 38: „Immature White-tails are quite blackish" en BENT, I937, p. 219). Bovendien komt volgens Peters (deel I, p. 232) de subspecies van Buteo albonotatus die voor het $O$. van noordelijk Zuid-Amerika in aanmerking komt, Buteo albonotatus abbreviatus Cabanis, als "resident” voor ,in the Pearl Islands and in Northern South America east to Suriname", zodat wel moet worden aangenomen, dat de donkere buizerden van het Noordelijke deel van Curaçao jonge exx. van $B$. albicaudatus zijn. Buteo albonotatus dient dus vooralsnog van de lijst van vogels der Benedenwindse Eilanden geschrapt te worden.

Ook op Bonaire zagen wij enkele exx. van de Witstaartbuizerd.

Pantion haliaetus carolinensis (Gm.). Van de Visarend zag ik een ex. op 2I Februari boven de St. Martha-baai, een op 27 Februari boven St. Kruisbaai (beide op Curaçao) en een op 28 Februari 1948 bij Lac (Bonaire).

Polyborus cheriway audubonii Cassin. De „Warawara” is nog steeds algemeen op Curaçao. Op Bonaire minder talrijk; wij zagen hier slechts één paar bij het Pekelmeer op 29 Februari 1948.

Falco sparverius brevipennis (Berlepsch). Noch RUTten noch DE Jong vermelden het voorkomen van de „Kinikini” op Bonaire. Ook wij zagen hier gedurende ons korte verblijf geen enkel exemplaar van deze soort. Hij schijnt hier dus tegenwoondig werkelijk te ontbreken. Peters (I93I) vermeldt hem nog voor Bonaire. Op Curaçao is hij algemeen.

Falco peregrinus anatum Bonaparte. Gedurende ons verblijf op de Benedenwindse Eilanden zag ik enkele Slechtvalken, ongetwijfeld doortrekkers en wel op 27 Februari een ex. bij St. Kruis (Curaçao), op 28 Februari één bij het Pekelmeer en op 29 Februari 19482 exx., resp. één bij Kralendijk en één bij Fontein (Bonaire). Deze soort wordt noch door RutTen noch door DE JONG vermeld.

Haematopus ostralegus palliatus Temminck 2). De Scholekster van de Atlantische Amerikaanse kusten schijnt weinig op de Benedenwindse Eilanden voor te komen; ik zag slechts één paar op 28 Februari 1948 bij Lac (Bonaire).

Squatarola squatarola (L.). De Zilverplevier, volgens RUTTEN en DE JONG nooit algemeen, was op 28 en 29 Febr. I948 zeer talrijk aanwezig langs het Pekelmeer (Bonaire).

Charadrius hiaticula semipalmatus Bonaparte. De Bontbek komt volgens Rutten en DE Jong in gering aantal op de Eilanden voor. Ik zag echter in de Oranjepan (Pekelmeer) op 29 Febr. 1948 een troep van ver over de 600 exemplaren.

2) Deze wordt naar het schijnt thans weer als eigen soort $H$. palliatus Temminck beschouwd! 
Numenius phaeopus hudsonicus Latham. Van de Regenwulp zag ik slechts één exemplaar en wel op 28 Febr. 1948 in de Witte Pan van het Pekelmeer (Bonaire). RutTen vergiste zich, toen hij "Phaeopus hudsonicus" vergeleek met onze Grote Wulp. Met deze komt wat de vorm aangaat Numenius americanus Bechstein, een grote bruine wulp, geheel overeen.

Arenaria interpres morinella (L.). Wat van de Zilverplevier gezegd werd, geldt eveneens voor de N.-Amerikaanse Steenloper, die ook op 28 en 29 Febr. 1948 talrijk was aan het Pekelmeer.

Crotophaga sulcirostris Swainson. Zoals Rutren reeds mededeelde, komt de Tsjoetsjoebi Pretoe zowel op Curaçao als Bonaire voor. Wij zagen hem geregeld, doch nooit talrijk, op Curaçao; op Bonaire enkele bij Dos Poos (29 Febr.) en een 12-tal bij „Bolivia” op I Maart 1948.

Ceryle a. alcyon L. Deze soort bezoekt Curaçao en Bonaire geregeld op de trek. Wij zagen op 20 Februari 1948 een ex. boven de Plaja di Sjon; op 2I Februari een 4 of 5 exx. boven de St. Martha-baai en op 22 Febr. 1948 één ex. boven het Spaanse Water (Curaçao). Op 29 Febr. I948 een of twee boven Slachtbaai (Bonaire).

\section{LITTERATUUR}

Rutren, M. G., 1931. Over de vogels van de Hollandsche Benedenwindsche Eilanden (Antillen). Ardea, vol. 20.

De Jong, M., 1948. De vogels van Curaçao, Aruba en Bonaire. Limosa, vol. 2I.

Peters, J. L., 194I-1948. Check-list of Birds of the World, I-VI. Cambridge (Mass.)?

Peterson, R. T., 194I. Field-Guide to Western Birds. Boston.

Bent, A. C., 1937. Life Histories of North American Birds of Prey, part I. United States National Museum, Bull. I67. 